\title{
Extrusion of Polyethylene/Polypropylene Blends with Microfibrillar-Phase Morphology
}

\author{
Martina Polášková, ${ }^{1,2}$ Roman Cermak, ${ }^{1}$ Tomas Sedlaček, ${ }^{1}$ Jakub Kalus, ${ }^{1}$ Martin Obadal, ${ }^{3}$ Petr Saha ${ }^{1}$
}

Extrusion of immiscible polymers under special conditions can lead to creation of microfibrillar-phase morphology, ensuring significant increase of mechanical properties of polymer profiles. Polyethylene/polypropylene blend extrudates with microfibrillar-phase morphology (polypropylene microfibrils reinforcing polyethylene matrix phase) were prepared through continuous extrusion with semihyperbolic-converging die enabling elongation and orientation of microfibrils in flow direction. Structure of extruded profiles was examined using electron microscopy and wide-angle $\mathrm{X}$-ray scattering. Tensile tests proved that extrudates with microfibrillar- phase morphology show significantly higher mechanical properties than the conventional extrudates. The presented concept offers possibility of replacing the existing expensive multicomponent medical devices with fully polymeric tools. POLYM. COMPOS., 31:1427- 1433, 2010. $\odot 2009$ Society of Plastics Engineers

\section{INTRODUCTION}

The blending of polyethylene with polypropylene has received considerable attention as they are two of the most commonly used thermoplastics. The reason is not only a favorable price/performance ratio, but also the versatility of these materials and very broad range of their possible modification $[1-4]$.

Just by controlling the relative amount of each component in the blend, the resulting properties are being considerably changed $[5,6]$. For instance, although the addition of polyethylene (PE) into polypropylene (PP) decreases the overall crystallinity of the blend, it simultaneously increases its impact strength $[6,7]$. On the contrary, the addition of polypropylene into polyethylene improves the environmental stress crack resistance of polyethylene [6], which is one of the most restricting factors of polyethylene usage in the medical industry [8] and has a positive effect on modulus and yield stress of the resulting blend $[6,9,10]$. However, final properties of the $\mathrm{PE} / \mathrm{PP}$ blend are not only characterized by the blend composition but also its phase morphology.

It was proved that properties of polymeric products made from immiscible polymer blends, such as PE/PP blend, are to a great extent influenced by the structure of the blend formed during its processing [11, 12]. Significant enhancement of mechanical properties brings for example concept of a composite of PP fibrils embedded in continuous PE matrix. The preparation of such composite is quite different from that of conventional composites, in so far as fibrils are not available as a separate material but are created during processing. One of the suitable methods of reaching this goal is cold drawing and subsequent annealing at fixed length $[1,13]$. Besides long and complicated manufacturing, this approach offers only discontinuous process with limited article dimensions, i.e., fibers, thin tapes, and films [10, 13-15].

Larger products (with similar microfibrillar-phase morphology) can be prepared during melt process under certain flow conditions [16-20]. Such flow condition can be achieved either by oscillating packing injection molding, whereby the microfibrillar-phase morphology is accomplished by oscillation and shearing of polymer melt in mould cavity using a pair of pistons that move reversibly with the same frequency during cooling $[21,22]$ or via extrusion process, where the elongational flow, causing the formation of microfibrillar structure, is achieved in the converging section of extrusion die [23]. 


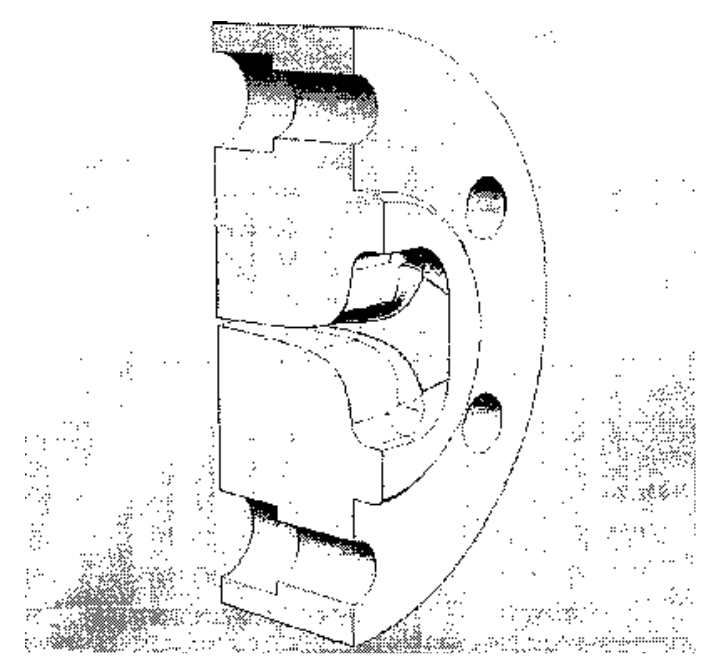

FIG. 1. Scheme of semihyperbolic geometry of the converging channel in extrusion die. The inlet section with diameter of $60 \mathrm{~mm}$ is followed by $55 \mathrm{~mm}$ long semihyperbolic converging section and outlet $2 \times 20 \mathrm{~mm}^{2}$ cross-section.

This article is focused on continuous preparation of in situ $\mathrm{PE} / \mathrm{PP}$ composites, consisting of $\mathrm{PP}$ fibrils in $\mathrm{PE}$ matrix to improve the mechanical properties of conventional PE profiles and at the same time to maintain their relatively high elasticity as an alternative of the conventional PE medical tubes and catheters [24]. Thus, various PE/PP blends were prepared and processed using extrusion line equipped with semi-hyperbolic converging die (enables sufficiently high elongational flow [25]). Resulting structure and properties of extrudates were subsequently studied and analyzed.

\section{EXPERIMENTAL}

\section{Materials}

Commercially available high-density polyethylene and isotactic polypropylene (as a reinforcing component) were

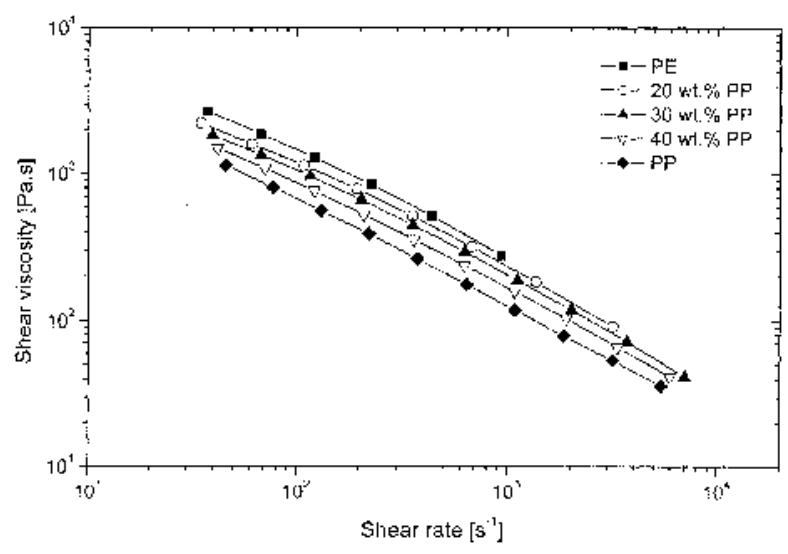

FIG. 2. Corrected shear viscosity as a function of corrected shear rate for compounded PE/PP blends and pure materials.

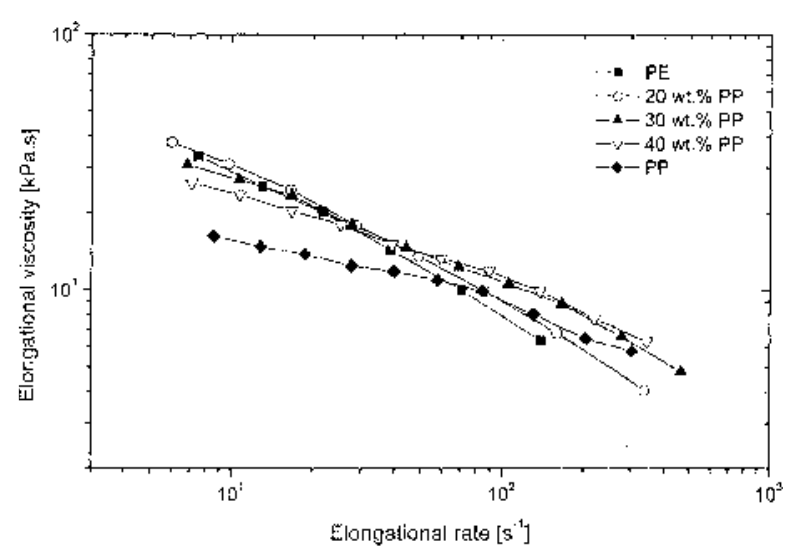

FIG. 3. Elongational viscosity as a function of elongational rate for compounded $\mathrm{PE} / \mathrm{PP}$ blends and pure materials.

chosen for this study. High-density polyethylene is characterized by melt flow index of $0.55 \mathrm{~g} / 10 \mathrm{~min}\left(2.16 \mathrm{~kg}, 190^{\circ} \mathrm{C}\right.$, ISO 1133), a weight-average molecular weight of 140,000 (GPC) and density of $952 \mathrm{~kg} / \mathrm{m}^{3}$ (ISO 1183), iso- tactic polypropylene is described as a material with melt flow index of $3.20 \mathrm{~g} / 10 \mathrm{~min}$ $\left(2.16 \mathrm{~kg}, 230^{\circ} \mathrm{C}\right.$, ISO 1133$)$, a weight-average molecular weight of 360,000 (GPC), an isotacticity index of 98\% (ISO 9113) and density of $910 \mathrm{~kg} / \mathrm{m}^{3}$ (ISO 1183).

\section{Compounding}

$\mathrm{PE} / \mathrm{PP}$ blends were prepared using counter-rotating twinscrew extruder at screw speed $35 \mathrm{rpm}$. The temperature of extruder ranged from $190^{\circ} \mathrm{C}$ (in the melting zone) to $210^{\circ} \mathrm{C}$ (in the metering zone and the die). The extruded blends with 20,30, and $40 \mathrm{wt} \%$ of PP were air-cooled and pelletized. For determination of the effect of compounding on morphology and properties of final extruded

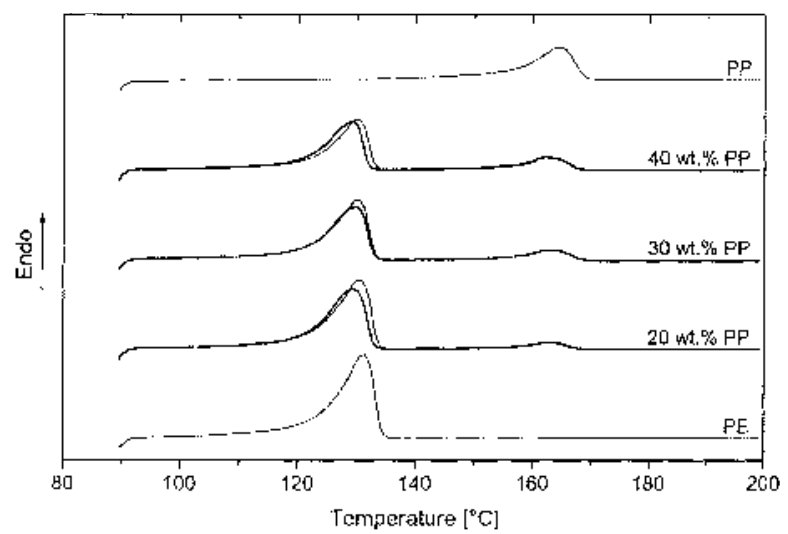

FIG. 4. Thermal scans of extrudates from pure, mixed, and blended polymers. The thin solid lines represent samples prepared from compounded PE/PP blends, and the thick solid lines are used for PE/PP mixtures. 


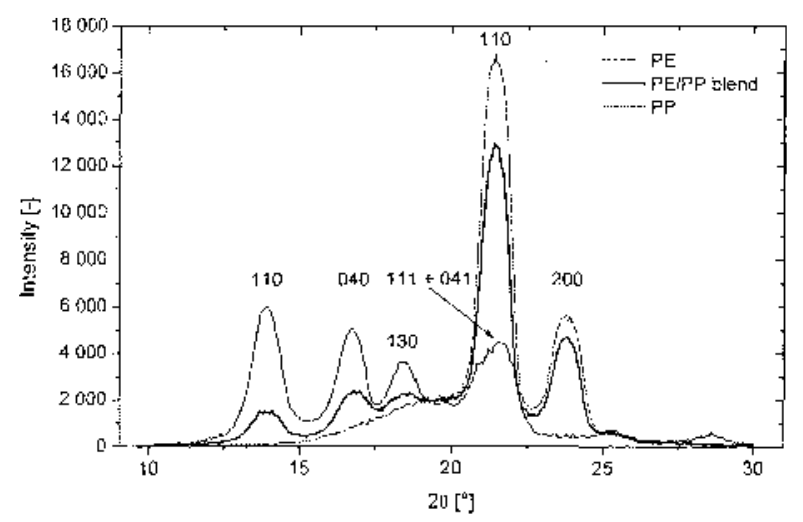

FIG. 5. Wide-angle $X$-ray scattering patterns of extmdates prepared from PE, PP, and PE/PP blend.

tapes, also hand-mixed polymer mixtures were prepared in the same weight concentrations.

\section{Extrusion}

Extrusion line consisting of (i) a single-screw extruder Brabender 30/25 L/D, (ii) a gear pump Zenith PEP II 1.2 $\mathrm{cm}^{3} / \mathrm{rev}$, and (iii) a flat extrusion die with $2 \times 20 \mathrm{~mm}^{2}$ outlet cross-section was used for final extrusion of tapes from prepared blends and mixtures. The polymer melt passing through die was firstly accelerated in semi- hyperbolic convergent section and subsequently cooled in calibration zone. The scheme of converging channel geometry is shown in Fig. 1. The inlet section, which has diameter of $60 \mathrm{~mm}$, is followed by semihyperbolic converging section with length of $55 \mathrm{~mm}$, and outlet cross- section of $2 \times 20 \mathrm{~mm}^{2}$. Constant extrusion rate was governed by a gear pump (20 rpm). Temperatures of extruder $\left(150,170,190,210^{\circ} \mathrm{C}\right)$, gear pump $\left(200^{\circ} \mathrm{C}\right)$, and die sections $\left(185^{\circ} \mathrm{C}\right.$ in cylinder, $170^{\circ} \mathrm{C}$ in converging and calibration zones) were constant throughout the experiment. No chemicals were used to modify the interface between the polymers. All the extrudates were solidified in the air without drawing.

\section{Rheological Measurement}

Twin bore capillary rheometer RH7-2 (Rosand Precision, Ltd., England), enabling simultaneous measurements with short (orifice) and long capillaries, was used for evaluation of rheological characteristics of both the blends and pure materials. As the chosen temperature in the die sections were in the range of 185 and $170^{\circ} \mathrm{C}$, the real melt temperature in the die could be expected close to $180^{\circ} \mathrm{C}$. Thus the rheological experiments were performed at temperature of $180^{\circ} \mathrm{C}$ in a constant piston speed mode at a shear rate range approximately from $10^{1}$ to $10^{4} \mathrm{~s}^{-1}$. The obtained apparent rheological data were corrected using Bagley and Rabinowitsch corrections and then elongational viscosity was computed via Cogswell method [26] implemented in Rosand software.

Differential Scanning Calorimetry

Thermal behavior of extrudates was investigated by the help of power-compensation differential scanning calorimeter (DSC Pyris 1 Perkin-Elmer Co., USA). Thin cross-sectional cuts ( 120 fim thick) microtomed from extruded tapes using a FOK GYEM OE-908 microtome were loaded into aluminium pans. Finally, the heating scans in the range of $50^{\circ} \mathrm{C}$ to $190^{\circ} \mathrm{C}$ were performed at heating rate of $10^{\circ} \mathrm{C} / \mathrm{min}$ in the nitrogen atmosphere. Obtained thermograms were utilized for calculation of melting temperature and heat of fusion.

\section{Wide-Angle X-Ray Scattering}

Wide-angle X-ray scattering was applied to determine degree of orientation in reinforcing PP phase. Experiments were carried out in transmission mode with HZG diffractometer. Radial scans of intensity vs. diffraction angle 29 were recorded in the range of $10-30^{\circ}$ by steps of $0.05^{\circ}$ and step scan interval of $5 \mathrm{~s}$ at ambient temperature.

\section{Scanning Electron Microscopy}

Scanning electron microscopy was used for observation of structure of extruded tapes. The extrudates were broken in liquid nitrogen and, subsequently, the fracture surfaces were coated by a thin gold layer and observed by scanning electron microscope Jeol JSM-35.

\section{Tensile Testing}

Tensile properties of extruded tapes at ambient temperature were tested by means of an Instron 8871 tensile

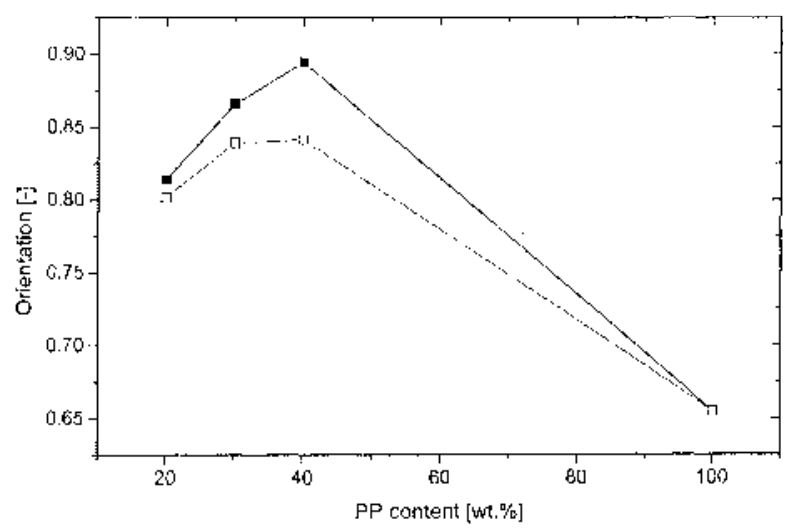

FIG. 6. Degree of orientation in extrudates from pure, mixed, and blended polymers as a function of PE/PP composition. The closed symbols stand for compounded PE/PP blends and open symbols represent PE/PP mixtures. 

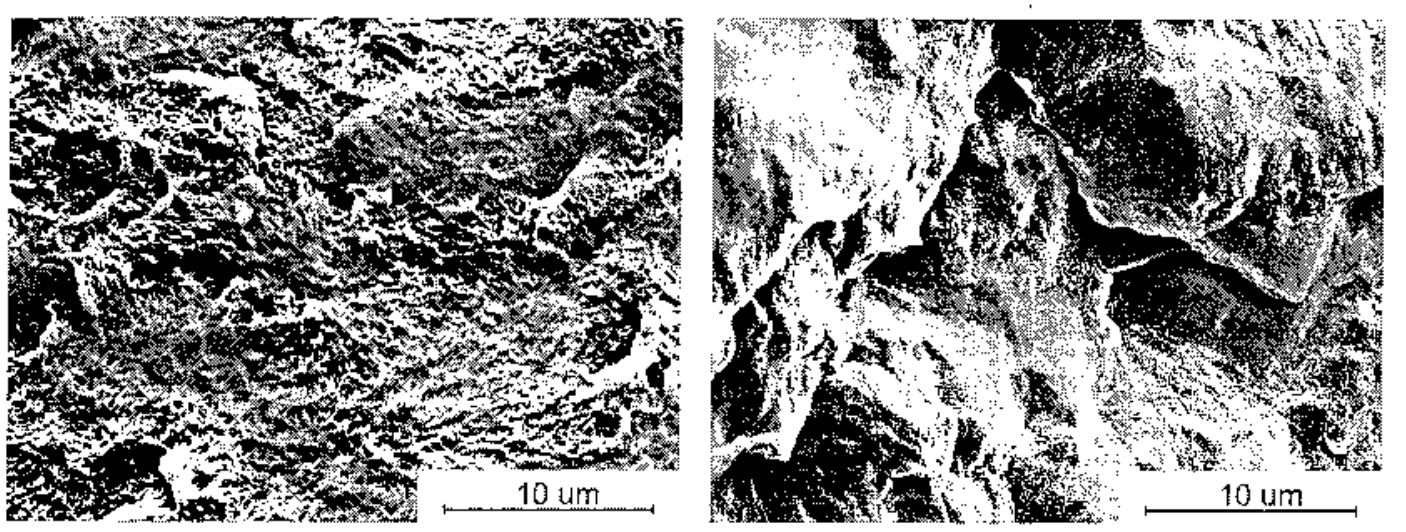

FIG. 7. Micrographs of the crack surface of the extrudates prepared from PE (left) and PP (right).

testing machine. Seven specimens with gauge length of $30 \mathrm{~mm}$, width of $\sim 3 \mathrm{~mm}$ and thickness of $\sim 2 \mathrm{~mm}$ were strained at initial rate of $1 \mathrm{~mm} / \mathrm{min}$ to $1 \%$ strain for accurate E-modulus determination. Then, the testing continued at the strain rate of $100 \mathrm{~mm} / \mathrm{min}$.

\section{RESULTS AND DISCUSSION}

Results of rheological experiments performed on both pure $\mathrm{PP}$ and PE and their blends are shown in Fig. 2. It is obvious that the lowest and the highest shear viscosity in the whole measured range of shear rates were obtained for pure $\mathrm{PP}$ and $\mathrm{PE}$, respectively' Shear viscosity of blends lies in the region between both pure materials, according to addition rule.

Furthermore, it was found that decreasing PP amount shifts position of flow curves to higher values of shear viscosity, and narrows measurable range of shear rates; while the shear viscosity of pure PE can be only measured to the shear rate of $937 \mathrm{~s}$ "1 due to flow instabilities, addition of $20 \mathrm{wt} \%$ of PP into $\mathrm{PE}$ shifts critical tested shear rate to $3700 \mathrm{~s}^{-1}$ and, finally, the viscosity of 30/70 PE/PP blend can be obtained in the whole chosen range of shear rates. In fact, this indicates that the blending of PP into PE broadens the interval of processing extrusion rates.

The elongational viscosity curves of both pure materials and their blends computed by Cogswell method are presented in Fig. 3. It can be seen that the elongational viscosity of pure PE is more sensitive to the elongational rate than that of pure PP. In the blends, the sensitivity of elongational viscosity to the elongational rate is notably changing with the $\mathrm{PE} / \mathrm{PP}$ ratio. While the decrease of elongational viscosity in 60/40 PE/PP blend with the elongational rate is rather moderate, the values of $80 / 20$ blend steeply drops.

Thermograms in Fig. 4 supply the information on melting behavior of extruded materials. As can be seen, the melting peaks of individual polymer phases can be clearly distinguished in both blends and mixtures. The maxima of individual peaks obviously correspond to the intensities of neat polymers, indicating total immiscibility of polymer pair used.

Regarding the processing of the blends, determined results of flow behavior of tested materials signify better stretching ability of PP macromolecules during extrusion, compared with those of PE. This can lead to the easier formation of PP microfibrils in PE matrix. Moreover, microfibrils creation is additionally supported by the fact that activation energy of PP is more than two times higher, as compared to PE [27]. Consequently, slight decrease of temperature (coupled with temperature drop in calibration zone) is reflected by dramatic increase in shear viscosity of PP, resulting in efficient fixation of the material in microfibrillar phase.

Molecular orientation of the individual phases in the blends can be determined using wide-angle $\mathrm{X}$-ray scattering. Unfortunately, in the case of PE/PP blend, the evaluation of crystalline orientation suggested by Trotignon and Lebrun [28] cannot be used, as the reflections necessary for this calculation are overlapped (see Fig. 5). Thus, the estimation of PP orientation in extrudates was based on the ratio between the intensities of (110) and (040) reflections, $O=/$ (no) $/ /($ iio ) + $1<040>$ -

Figure 6 shows orientation of PP in extruded tapes as a function of PP content. Results revealed that the orientation in blends is higher compared to pure PP extrudates. Moreover, PP orientation increases with rising amount of $\mathrm{PP}$ in the blend composition. However, it is clear that this tendency is more pronounced in blends reflecting significant influence of twinscrew compounding on quality of resulting structure.

It is noteworthy that orientation of neat PP during extrusion process can be achieved with the die temperature no higher than $140^{\circ} \mathrm{C}$ [29], which verifies the fact that the blending of PP with PE significantly broadens processing conditions under which the PP fibrils can be formed.

The scanned micrographs of extrudate fracture surfaces are shown in Figs. 7 and 8. Although the micrographs of 

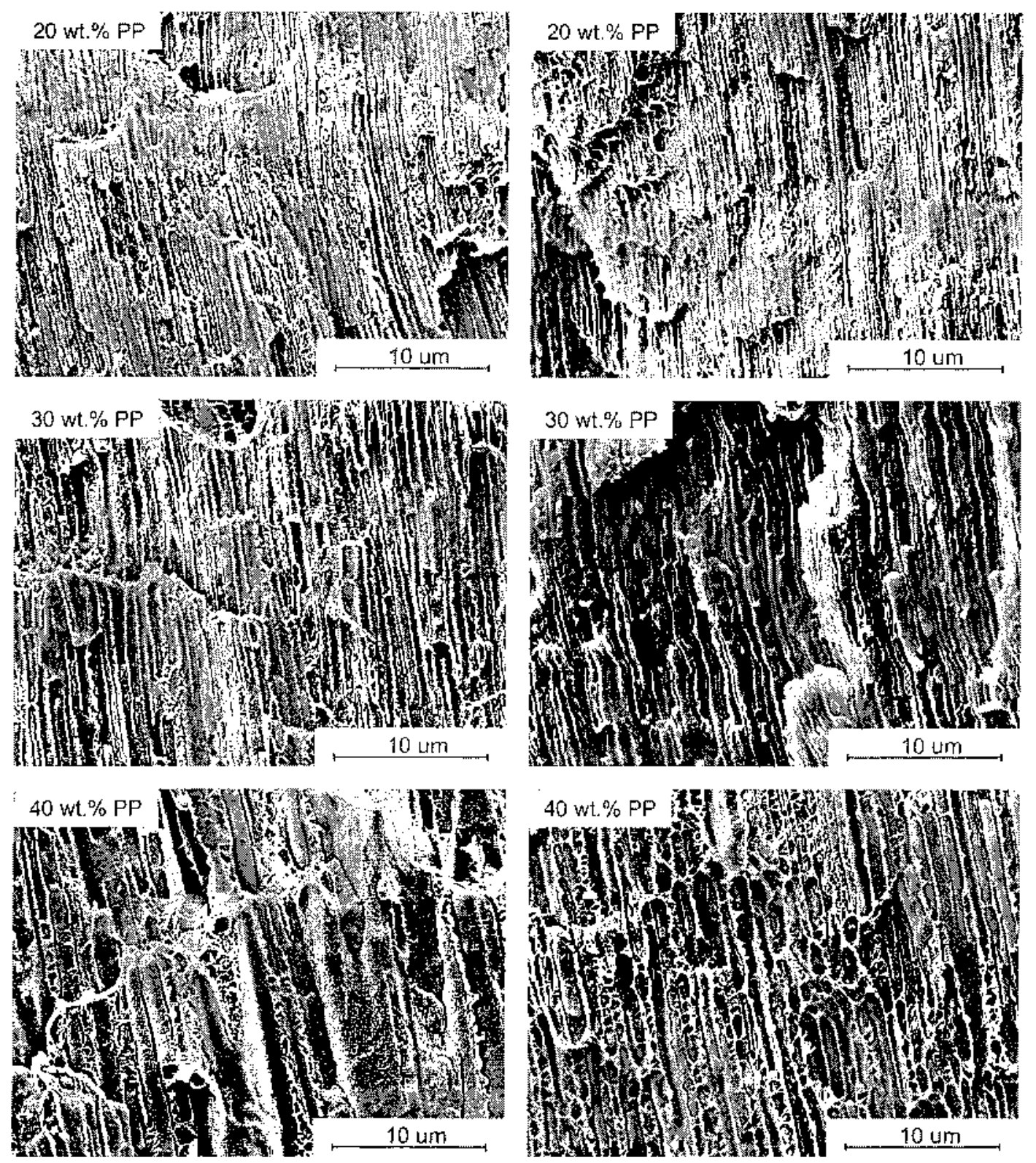

FIG. 8. Micrographs of the crack surface of the extradâtes prepared from compounded PE/PP blends (left) and PE/PP mixtures (right); PP content increases from top to bottom. PP microfibrillar-phase is rather manifested by dark color, whereas PE matrix is demonstrated by bright color.

pure extrudates show isotropic structure, the morphology of the tapes extruded from blends and mixtures manifests fairly twophase structure.

The morphology evolution of PE/PP blend is generally accomplished by two steps. In the first step, a significant reduction in the particle size of the dispersed phase is observed from millimeter to micron scale [20]. During extrusion, it takes place in short axial length after solid conveying. Indeed, compounding process before extrusion itself strongly supports the break-up of dispersed phase into fine particles. In the second step, the drops of fibril- lar-forming component are stretched and coalesced in the direction of flow, as it is obvious from Fig. 8, where the morphology of the tapes extruded from blends and mixtures is depicted. Polymer blend with such morphology may be regarded as a suspension system filled with thermoplastic fibrils lying with respect to the size of fibrils between common macrocomposites and molecular composites (e.g., with single rod-like molecules or bundles of them) [30].

It is also evident that the structure of extrudates gradually changes from fine-fibrillar morphology to coarse co-continuous phase structure, in respect of the PP content increase. This structure gradation is clearly 


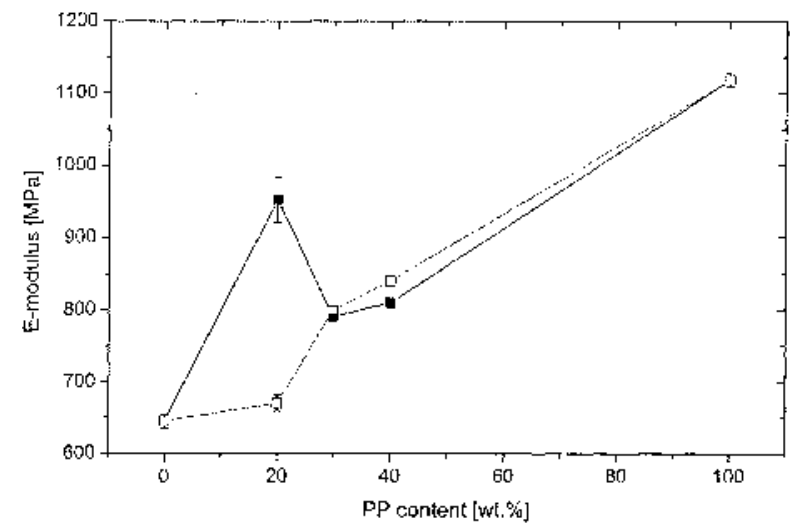

FIG. 9. Dependence of modulus of extrudates on PE/PP composition. The closed symbols stand for compounded PE/PP blends and open symbols represent PE/PP mixtures.

pronounced in the extrudates prepared from blends, while the diameter of PP domains in extrudates from mixtures is not directly related to the PP content. It is worth noting that a fine microfibrillar structure can be formed in one processing step, without previous compounding of material pair.

The elastic modulus of extruded tapes as a function of phase composition is presented in Fig. 9. The modulus reflects the tensile behavior of the material under a minute deformation and virtually static test conditions (strain rate $1 \mathrm{~mm} / \mathrm{min}$ ), i.e. in the ideal elastic region. Predominantly, values of modulus in both blends and mixtures follow the additivity rule, i.e., they correspond to the values of blend component with respect to the phase composition. However, the extrudates from blend containing 20 wt $\%$ of PP show a significant positive deviation in modulus, compared with the values predicted by additivity rule. These results indicate a synergic effect in this blend based on: (i) degree of orientation in PP phase; as proved by wideangle X-ray scattering, $\mathrm{PP}$ phase in extruded blends pos-

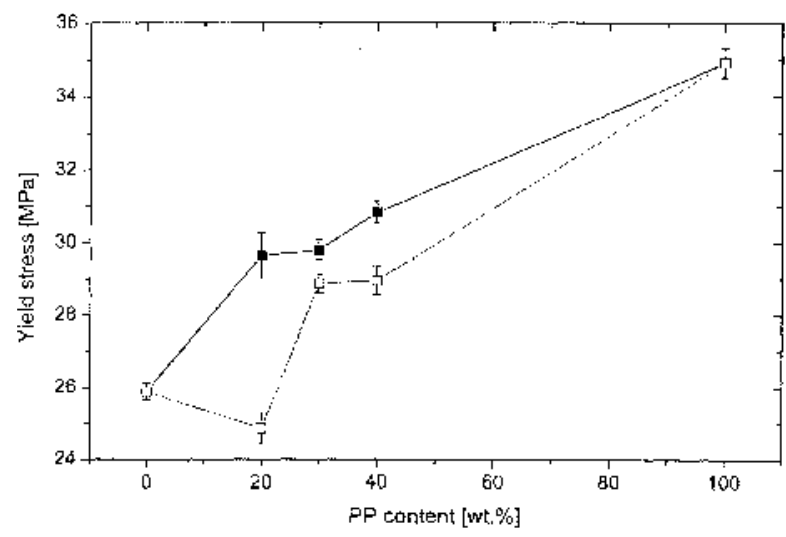

FTG. 10. Dependence of yield stress on PE/PP composition of the extruded specimen. The closed symbols stand for compounded PE/PP blends and open symbols represent PE/PP mixtures.

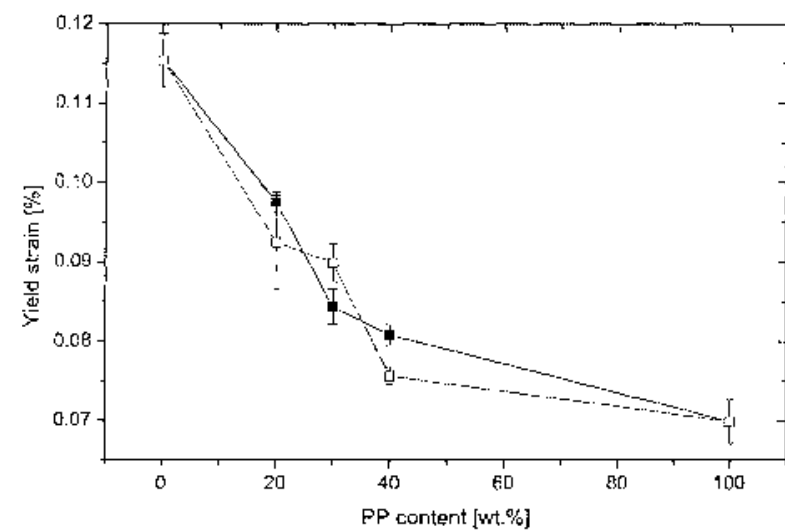

FIG. 11. Dependence of strain at yield on PE/PP composition of the extruded specimen. The closed symbols stand for compounded PE/PP blends and open symbols represent PE/PP mixtures.

sesses significantly higher level of macromolecular orientation than the extrudate from pure material, (ii) aspect ratio of microfibrils; as demonstrated by the micrographs from scanning electron microscopy, the finest fibrils were found in the extrudate from the blend containing $20 \mathrm{wt} \%$ of PP.

Stress and strain at yield of extruded tapes were measured to assess the potential of the material to withstand tensile stress within a semi-dynamic test (strain rate $100 \mathrm{~mm} / \mathrm{min}$ ). From the designing point of view, the yield stress represents the tensile strength of polymers because further deformation leads to a broad nonreversible transformation of the material during which the original structure is oriented into stress direction. Yield strain, on the other hand, can be considered as a ratio of material deformability within a low-strain region or as a measure of ability of material to follow the tortuous path to its ultimate destination without occurrence of any failure. This is particularly asked for medical guide catheters or tubes. The values of yield stress and strain of the extrudates, with respect to the phase composition, are displayed in Figs. 10 and 11. It is clear that the yield stress increases with rising amount of PP, while, at the same time, yield strain decreases. Compared with the values predicted in accordance with additivity rule, the yield stress of tapes extruded from blends displays positive deviation, while extrudates from mixtures exhibits rather negative deviation. This discrepancy can be ascribed to differences in morphology and slightly higher phase synergism resulting from the process of twin-screw extrusion. On the other hand, the impact of the compounding on yield strain values cannot be unambiguously assessed because of generally higher standard deviations

\section{CONCLUSION}

The aim of this work was preparation of microfibrillar- phase morphology in the PE/PP blends with $\mathrm{PP}$ as a minority component. For these purposes an extrusion line 
based on conventional single-screw extruder and semihyperbolic-converging die was used. It was proved that in one processing step can be achieved the formation of microfibrillar structure in extrudates from both twin-screw compounded and hand-mixed polymer blends in all tested compositions (20, 30, and $40 \mathrm{wt} \%$ of PP).

Regarding the fact that the best results in stiffness were achieved using blends with the lowest PP amount (namely $20 \mathrm{wt}$ $\%$ of PP), research of blends with low PP content (e.g. 5-25 wt $\%$ varying in finer PP concentration steps will follow. Nevertheless, current results indicate microfibrillar-phase composites from PE/PP blends prepared by continuous extrusion are an attractive way to improve the mechanical properties of existing PE medical devices. The potential of present technique thus promises easier, shorter, and more economic production of profiles (tubes, catheters, etc.) in contrast to sophisticated present- day production of multi-layer profiles.

\section{ACKNOWLEDGMENTS}

The authors wish to express their sincere appreciation to Prof. Martin Zatloukal for help with rheological measurements and valuable discussions of their results.

\section{NOMENCLATURE}

$\begin{array}{ll}I_{(110)} & \text { Intensity of }(110) \text { reflection } \\ I_{(040)} & \text { Intensity of }(040) \text { reflection } \\ O & \text { Orientiation (ol PP phase) } \\ \mathrm{GPC} & \text { Gel Permeation Chromatography } \\ \mathrm{J} / \mathrm{D} & \text { Length to Dianeter ratio } \\ \mathrm{PE} & \text { Polyethylene } \\ \mathrm{PP} & \text { Polypropylene } \\ \mathrm{TPm} & \text { revolution per minute } \\ \text { wt } \% & \text { weight percentli }\end{array}$

\section{REFERENCES}

1. E.S. Sherman, /. Mater. Sei., 19, 4014 (1984).

2. M.M. Dumoulin and P.J. Carreau, Polym. Eng. Sei., 27, 1627 (1987).

3. J.W. The, A. Rudin, and J.C. Keung, Adv. Polym. Technol., 13,1 (1994).

4. N. Kukaleva, F. Cser, M. Jollands, and E. Kosior, J. Appl. Polym. Sei., 80, 831 (2001).

5. J. Li, R.A. Shanks, and Y. Long, J. Appl. Polym. Sei., 76,1151 (2000).

6. S. Jose, A.S. Aprem, B. Francis, M.C. Chandy, P. Werner, V. Alstaedt, and S. Thomas, Eur. Polym. 40, 2105 (2004).
7. A.K. Gupta, Y.B. Gupta, R.H. Peters, W.G. Harland, and J.P. Berry, /. Appl. Polym. Sei., 27, 4669 (1982).

8. R.C. Portnoy and A. Lustiger, Medical Plastics: Degradation, Resistance \& Failure Analysis, Plastic Design Library, Norwich, (1998).

9. O.F. Noel, and J.F. Carley, Polym. Eng. Sei., 15, 117 (1975).

10. A.J. Lovinger, and M.L. Williams, J. Appl. Polym. Sei., 25, 1703 (1980).

11. J. Lyngaae-Jorgensen and L.A. Utracki, Polymer, 44, 1661 (2003).

12. Y.K. Lee, Y.T. Jeong, and B.K. Kim, Polym. Eng. Sei., 31, 944 (1991).

13. P. Schmidt, J. Baldrian, J. Scudla, J. Dybal, M. Raab, and K.-J. Eichhorn, Polymer, 42, 5321 (2001).

14. M. Kojima and H. Satake, J. Polym. Sei.: Polym. Phys. Ed., 22, 285 (1984).

15. B. Gross and J. Petermann, J. Mater. Sei., 19, 105 (1984).

16. V.E. Dreval, G.V. Vinogradov, E.P. Plotnikova, M.P. Zabugina, N.P. Krasnikova, E.V. Kotova, and Z. Pelzbauer, Rheol. Acta., 22, 102 (1983).

17. M.P. Zabugina, E.P. Plotnikova, G.V. Vinogradov, and V.E. Dreval, Int. J. Polym. Mater., 10, 1 (1983).

18. M.V. Tsebrenko, Int. J. Polym. Mater., 10, 83 (1983).

19. L.A. Utracki, Polymer Alloys and Blends: Thermodynamics and Rheology, Hanser Publishers, Munich, (1989).

20. J.S. Hong, K.H. Ahn, and S.J. Lee, Rheol. Acta., 45, 202 (2005).

21. G. Zhang, Q. Fu, K. Shen, L. Jian, and Y. Wang, J. Appl. Polym. Sei., 86, 58 (2002).

22. B. Na, K. Wang, Q. Zhang, R. Du, and Q. Fu, Polymer, 46, 3190 (2005).

23. R. Cermak, M. Polášková, J. Kalus, and M. Öbadal, 4th Annual European Rheology Conference AERC 2007, Napoli, Italy, (2007).

24. S. Holbe, G.W. Ehrenstein, and M. Giese, 18th Annual Meeting of the Polymer Processing Society, Guimares, Portugal, (2002).

25. A.V. Pendse and J.R. Collier, / Appl. Polym. Sei., 59, 1305 (1996).

26. F.N. Cogswell, Polym. Eng. Sei., 12, 64 (1972).

27. T. Sedlaček, R. Cermak, B. Hausnerova, M. Zatloukal, A. Boldizar, and P. Saha, Int. Polym. Process., 20, 286 (2005).

28. J.P. Trotignon, J.L. Lebrun, and J. Verdu, Plast. Rubber. Process. Appl., 2, 247 (1982).

29. R. Čermák, M. Obadal, V. Habrová, K. Stoklasa, V. Verney,

S. Commereuc, and F. Fraisse, Rheol. Acta., 45, 366 (2006).

30. M. Evstatiev, N. Nicolov, and S. Fakirov, Polymer, 37, 4455 (1996). 